\title{
ASTUCIAS BÍBLICAS*
}

André Wenin ${ }^{1}$

"He aquí que yo los envío como corderos en medio de los lobos, sean astutos como la serpiente pero sencillos (inocentes) como las palomas"

$\mathbf{E}$

ste es el consejo que según Mateo, y él únicamente, Jesús da a sus discípulos al enviarlos en misión. Sabiendo que se arriesgan a ser una presa fácil para los lobos de la sociedad religiosa de la época (ef. Mt.10,17-25), él les invita a mostrase astutos como la serpiente, prudentes, taimados con esa astucia que la sabiduría otorga a buen criterio a pesar de no perder nada de su candor, de su inocencia. Extraño consejo que no se esperaría nunca escuchar de los labios del propio Jesús, pero de todos modos al dar a Jesús la autoría de este hecho el evangelista Mateo se inscribe en la más pura tradición bíblica. Y la imagen que él utiliza nos envía hasta el primer personaje astuto que encontramos en la Biblia hebrea.

Y es que la primera figura bíblica que será nombrada es la serpiente del Génesis (Gn 3,1), quién aunque utiliza su inteligencia para engañar, se le debe reconocer, junto con el narrador, una sutileza que no tiene igual. Se la ve, así inducir la falsedad, tal como si fuera una verdad. En la orden que ha dado Dios, el Señor, ha invitado al ser humano a comer de todos los árboles del jardín, excepto de "el árbol para conocer bien y mal". Apoyándose sobre esta palabra, la serpiente interpela a la mujer diciéndole: Así que entonces, Dios ha dicho: "no comerán de todos los árboles del jardin..." En realidad, la serpiente tiene razón al decir que ellos no pueden comer de todos los árboles ya que Dios ha apartado uno a su guisa. Pero su frase es ambigua, porque en hebreo ello puede entenderse de otra forma, al punto que algunos traductores escriben, "ustedes no comerán de ningún árbol del jardín". Es esto lo que la

\footnotetext{
* Este texto corresponde a una ponencia presentada en el coloquio sobre "la ruse" celebrado en la Universidad de Lovaina en la primavera del 2001, y que será publicado por la "Revue du Mauss" en el 2004. Traducido por Ximena Abril C.
} 
mujer comprende, y ella rectifica inmediatamente diciendo que ellos comen de los otros árboles. Pero jugando sobre lo falso y lo verdadero, la serpiente insinúa una duda a la mujer: le hace ver en Dios a un ser que prohíbe, escondiendo cuidadosamente una de sus caras, aquella del Dios que en vez de prohibir ha dicho: De todos los árboles del jardín, tu comerás (Gn. 2, 16)

Pero la trampa es todavía más sutil. En efecto, el Señor Dios ha dado la orden utilizando un singular "tú". En este sentido, la prohibición viene a imponer un límite a uno de los sujetos de modo de hacerle ver la estructura de las relaciones justas, esto es tan cierto que el individuo humano no puede encontrarse sin un "no", uno al menos que lo limite y al mismo tiempo despierte su deseo. Es a esto a lo que Dios parece inducir, cuando da la orden a un tú calculando instaurar algún otro tipo de relación con el otro "tú" -es lo que relata la continuación del capítulo, cuando habla de la venida de la mujer. En esta treta, la serpiente juega con este elemento. Según ella, en efecto, la orden ha sido dada a un "ustedes" . La manera de hacerlo está llena de sutileza.

Así que al expresarse por usted, la serpiente hace notar el límite que Dios pone, no entre un "tu" y otro "tu", sino entre un usted y Dios. De hecho, aquel que en lugar de despertar el deseo del sujeto haciéndole ver su límite, frustra el deseo y priva a los humanos de aquello que podría satisfacer su deseo. Dios ya no es el ser benefactor que obra en aras de la vida, sino un ser malvado, un rival que impide vivir plenamente. De esta forma la serpiente consigue instalar la desconfianza necesaria para el éxito de su plan, un plan disimulado y que no se comprenderá en toda su magnitud, sino que cuando ya sea demasiado tarde.

Sobre esta base, es posible ya distinguir los parámetros de la treta. Ella juega sobre el deseo de aquel al que se le oye engañar para desequilibrar -como hacen los judokas- utilizando la fuerza del propio deseo del contendor. Ella recurre con finura a todas las potencialidades del lenguaje humano y del poder que esta obtiene sin la cual sería ineficaz como vehículo de relación y de comunicación, ya que por medio del lenguaje se trata de hacer creer. Es por esta razón que la trampa va a la par con el disimulo, con lo no dicho, pues es importante que el otro permanezca ciego a propósito de lo esencial, que debe quedar velado para los ojos. 
Dicho esto, en el primer Testamento, la trampa es más bien valorizada. ¿Es esto sorprendente, sobre todo cuando se trata de un pueblo que por lo general ha vivido una situación de debilidad? Muchas narraciones ponen en escena la treta, principalmente en los dos libros: de una parte el Génesis, en donde padres e hijos, hermanos, hermanas, cuñados, hilan sin fin de lo más fino antes de llegar a lo que en realidad desean. De otra parte el libro de Samuel donde la treta se despliega en un contexto político entre personas que intentan hacerse de la realeza o mantenerse en ella. También el libro de la Sabiduría habla de la treta o del engaño, de una manera frecuente. Así el término hebreo que se utiliza para designar un engaño, hmr, tiene connotaciones bastantes amplias: es la cualidad de quién es hábil, astuto y sabe adaptarse a diferentes situaciones. La LXX lo traduce por la palabra panourgi-a aquel que ha desarrollado en sí la capacidad de hacer todo, de ahí la inteligencia, la habilidad -todos estos rasgos de sabiduría $(\operatorname{Pr} 8$, 12-14) He aquí lo que una buena educación permite adquirir a un niño inocente para que él pueda avanzar en la vida como un sabio (Pr. 1,4; 8,5; ver 15,5; 19,25 y Si 6,32). Así según los proverbios, le $u w r$ /vigila su modo de ser $(14,8)$ y sabe guardar sus sentimientos para sí mismo $(12,16)$; ama el conocimiento $(14,18)$, pero traga todo lo que se le dice $(14,15)$; no reacciona de otro modo que a su buen criterio $(13,16)$ y no dice lo que él sabe solo en el momento adecuado $(12,23)$; sabe anticipar los golpes fuerte y ponerse al abrigo cuando lo necesita $(22,3)$. En ese contexto semántico, la $\mathrm{hmr}$ [como treta, significa una forma particular de sabiduría o algo como una inteligencia práctica que supone las cualidades que acabo de enumerar. Pero no todos los sabios de la Biblia están tan positivos a propósito del engaño o de la treta como el libro de los Proverbios, esta antología de antiguas máximas. El libro de Job en particular se muestra crítico con respecto a una sabiduría y un engaño que pueden ser usadas con malos fines, y que pueden servir para urdir el mal y aplastar al más débil (Jb 5, 12-13, ver Ps. 83,4 y Ex. 21, 14).

En las páginas que siguen, yo quisiera recorrer rápidamente algunas narraciones para intentar encontrar una fenomenología bíblica del engaño. Yo voy a clasificar estas narraciones en función del juzgamiento ético que el narrador sugiere, directamente o no, sobre la treta que él cuenta. Hay astucias que son descritas de ma- 
nera neutra; otras son juzgadas negativas; otras todavía se las juzga positivas. Evocando estas páginas de la Biblia hebrea, yo quisiera intentar de una parte aclarar algunas fuentes de la treta y de otra parte verificar si una lógica preside a los juicios morales en tanto estos son formulados y ver si ciertos elementos que constan determinan la apreciación positiva o negativa. Pero antes de entrar en los textos, hay que precisar que, desde un punto de vista literario, la narración de un engaño es, siempre, dada por el narrador, la ocasión de manipular la ironía en vista de ciertos personajes. En efecto, el engaño supone que el personaje engañado no sepa lo que sabe el engañador (astuto). También la narración conduce a este a decirle al lector lo que ocurre, de suerte que este vea que tal o cual personaje va ha hacerse estafar, lo que, generalmente lleva en sí un efecto altamente irónico.

\section{El engaño no calificado moralmente}

\subsection{El engaño de los Gabonitas (Josué, capítulo 9)}

La primera parte del libro de Josué relata la conquista por Israel del pueblo de Canaan. El mandato de Dios para esta conquista es la de exterminar las naciones y ocupar el país. A partir de la entrada de Israel en Canaan, las ciudades fortificadas de Jericó y de Aï cayeron, lo cual impresiona a los habitantes de la región. Queriendo reaccionar, ciertos reyes formaron una coalición para intentar detener el avance de Josué en un enfrentamiento armado $(9,1-2)$. Contrariamente a estos, otros optan por la astucia: estos son los habitantes de la ciudad de Gabón y de los alrededores. Temerosos de la perspectiva que les espera, intentan el todo por el todo para salvar sus cabezas, como ellos mismos lo dirán más tarde (v. 24).

Sabedores de que Josué ha recibido la orden de no hacer alianzas con los habitantes del pueblo de Canaan, los Gabonitas se dirigieron al campo israelí, a cinco o seis leguas de su propio pueblo, arreglándoselas para hacerles creer que vienen de lejos, y que eran extranjeros. Cambiaron de apariencia: cambiaron sus asnos con viejos morrales y con viejas perras de vino rotas y recocidas; tenían en sus pies viejas sandalias que daban la impresión de 
haber sido arregladas muchas veces y sobre ellos viejos vestidos; todo el pan que ellos llevaban estaba endurecido y casi en migas (v. 4-5). Una vez en el campamento, ellos dijeron que habían venido de muy lejos para postrarse a los pies de Josué y de su pueblo, como sus servidores y vasallos, a todo esto, glorificando al Dios de Israel por todas las grandes obras que había hecho en su favor. Cuando sus interlocutores israelitas ponen en duda sus declaraciones, ellos sacan su pan seco agregando que estaba caliente cuando salieron de sus casas. Así también exhiben sus perras recocidas y sus viejos vestidos usados como signo del largo y penoso viaje que ellos han debido efectuar. Entonces, sin consultar a Dios, los israelitas aceptan en señal de alianza las ofrendas que les ofrecen los emisarios de Gabón, mientras Josué sella un pacto que les asegura el Salmo y la vida salva. Tres días más tarde, Israel comprende con rabia y contrariedad, que estas gentes en realidad eran sus vecinos. A pesar de todo, Josué, respeta la palabra dada y él acepta a sus nuevos vasallos a su servicio, les carga de trabajos duros reservados a los siervos. $Y$ cuando son víctimas de la agresión los reyes vecinos (capítulo 10), Israel va en su ayuda, como un amo leal.

¿Cómo describe este texto al Engaño? Es una estrategia de seres en posición de debilidad que quieren imponer su deseo de vida, irreconciliable con la voluntad de muerte de sus opositores, pero que por la fuerza no podrían conseguir. Así que despliegan una puesta en escena que enmascara una pare de la realidad y permite volver creíble, un lenguaje falso. Pero este juega sobre lo que el enemigo va a llevarse. No solamente este desvanece las objeciones previsibles, sino que sobre todo está dirigido a agradar. Así los Gabonitas hablan del Dios nacional, quien es el orgullo de los israelitas, de su reputación que se extiende a lugares lejanos, de los grandes momentos de su historia reciente (cf. V. 9-10). De esta forma ellos les hacen creerse como merecedores a que se emprenda un viaje tan largo y extenuante, solo para venir a postrarse a sus pies y volverse sus súbditos. He aquí el por qué, Josué y los notables caen en su juego. Porque, sobre todo cuando se alaba su fuerza, el poderoso está tan seguro de sí mismo que ni siquiera piensa que alguien pueda intentar engañarlo. 
Pero el engaño o la treta no solo les pertenece a los débiles. Los fuertes pueden igualmente recurrir a ella. La historia de Jacob la ilustra de una manera divertida. Huyendo de la cólera de su hermano a quién gracias a un engaño, él le roba el derecho de primogenitura y la bendición paterna, Jacob llega al pueblo de los arameos donde se reencuentra con la familia de su madre. Apenas ha llegado, él conoce a Raquel, una prima de quien se enamora en el acto. Es entonces acogido por el padre de ella, su tío Laban, quien lo invita a trabajar para él y le propone fijar él mismo su salario. Jacob escoge entonces servirle por siete años para recibir en matrimonio a Raquel, la más pequeña de las hijas, que es mucho más bonita que Lea su hermana mayor. Laban sella su trato. Siete años más tarde, este organiza las nupcias. Según la costumbre supuesta por el relato, la novia permanecía velada hasta la noche de las nupcias. Y he aquí lo que el narrador cuenta: Laban reunió a toda la gente del lugar y dio un festín. La noche, él tomó a su hija Lea y se la lleva a él (Jacob) y este vino hacia ella. Y Laban le da a Zilpa su sirviente, como sirviente para su hija Lea. A la mañana siguiente, ¡he alli que era Lea! Y Jacob dice a Laban: “¿Qué has hecho? ¿No era por Raquel que yo te he servido? ¿Por qué me has engañado?" Y Laban dice a Jacob: "En este lugar no se puede dar a la más joven antes que a la mayor. Termina esta semana (de nupcias) y yo te daré también a ella por el servicio que tú me rendirás por otros siete años". Y Jacob así lo hizo. (v. 22-29)

La treta, es aquí una estrategia del jefe. Para garantizarse un obrero -del que el narrador nos dirá más tarde, cuan eficiente era-, Laban no negocia un nuevo contrato para evitar el tener que entrar en una situación de fuerza. El prefiere tomar un desvío, más seguro a sus ojos, para imponer su deseo a las eventuales veleidades de la libertad de su yerno. De nuevo, una puesta en escena es necesaria; ello implica un juego de simulación que permite el uso de un vestuario -astucia suplementaria con que Jacob había engañado a su padre, ayudándose de un traje (capítulo 27) del mismo modo va a ser engañado él...Pero aquí, no hay necesidad de mentira para la trampa en sí misma- el artificio no viene al caso sino en el momento de la justificación, para anticipar toda acusación de deshonestidad. La simulación es suficiente para inducir al error, ya 
que esta viene a reforzar otra pérdida de visión sobre la que Laban especula, aquella del amor. Lo que él sabe es que, como el narrador lo dice, durante los siete años, Jacob no veía el momento, tan enamorado él estaba (v.20). Así mismo, en el momento de las nupcias, el enamorado está tan seguro de que el momento tan ansiado ha llegado, que no piensa en desconfiar de un golpe embozado. Así es que contando con la predisposición de la parte engañada es como funciona la trampa.

\section{Malos engaños}

\subsection{David, Urías y Nathan (2 Samuel, capítulos 11-12)}

En los dos casos que yo evoqué hasta aquí, la treta no es objeto de una apreciación moral en el texto. Pero no siempre es así. Inclusive frecuentemente, la treta es calificada en la narración, ya sea por el narrador o por uno de los personajes. Así que hay engaños presentados bajo una mala perspectiva. Es el caso del engaño del rey David. Conocemos la historia. Mientras que la armada está en campaña, el rey David permanece en Jerusalem. Una noche, de la terraza de su palacio, él ve una mujer maravillosa que toma un baño. Recaba informaciones sobre ella, conoce su nombre, ella es Betsabé, la mujer de Urías, un capitán de la armada. Aunque él la sabe casada, la hace venir y se acuesta con ella. Encinta, la mujer previene al rey quien hace volver al soldado del frente pretextando tener un informe de la guerra. El lo invita a ir a su casa, esperando sin duda que este se acostará con su mujer y podrá pasar por padre del niño. Pero, respetuoso de las reglas de la guerra y solidario con sus camaradas quienes viven difícilmente, Urías pasa la noche con la guardia. David insiste. Incluso va a embriagar al marido engañado, con la esperanza de que una vez su voluntad adormecida, este cederá al deseo por su mujer.. Pero todo es en vano: Urías pasa la noche en el patio de la guardia. También, al día siguiente, David recurre a grandes medios. Confía a Urías una carta para Joab, el general de la armada: su carta de condena a muerte. En esta, el rey ordena a Joab ubicar a Urías en lo más arduo de la batalla y luego retirarse para que él muera en combate. Así su muerte es tomada como uno de los hechos de la guerra y David se casa con la viuda. Pero, concluye el narrador, lo 
que David hizo fue malo a los ojos de Adonai $(11,27)$, quien va ha hacérselo saber por medio del profeta Nathan (cap. 12).

El rey desplegó entonces su estrategia en dos tiempos. Primero, calculó sobre el deseo que supone en Urías para intentar realizar su propio deseo que disimula cuidadosamente: Disfrazó su falta inicial, sin tener que buscar soluciones extremas. Pero cuando la maniobra desemboca en la honestidad de Urías -o sobre la inteligencia de aquel que no ha tardado en adivinar el secreto-, David imagina otra trampa, más cínica pero mucho más eficaz, para conseguir su objetivo. La trampa del poderoso se vuelve necesaria cuando, por una razón u otra, la fuerza no daría resultado como fue el caso con Laban.

Así, en el asunto que nos ocupa, está claro que si el rey recurre a la fuerza contra el marido que él ha engañado, su injusticia se hará evidente a la luz del día y su legitimidad no sería comprometida. Es entonces para salvar las apariencias que David engaña porque de estas apariencias podría depender su poder. Pero Dios condena el segundo engaño. Si el primer estratagema hubiera tenido éxito la narración habría sin duda producido una sonrisa sin más. Pero el segundo engaño tiene como fin cubrir la arbitrariedad del poderoso y su real cinismo. Esta es movida no por el interés de hacer mover positivamente una situación, sino al contrario, por el deseo de separar definitivamente a aquel que obliga a tal maniobra.

Es sin duda por esto que el profeta Nathan va el mismo a recurrir a una treta para desequilibrar al rey. Mientras David cree que todo lo que está bien termina bien, Nathan es enviado por Adonai. Este llega donde el rey para presentarle un caso en el cual él debe actuar en calidad de juez. El caso presentado al rey es ficticio y refleja a groso modo lo que David ha hecho, aspecto que naturalmente él ignora. Es la historia de la injusticia flagrante de un gran propietario que, sin ninguna piedad arrancha a un pobre su única ovejita, para matarla y servirla a un huésped frente al cual, este tiene que parecer buen anfitrión. Lleno de cólera David muestra que es un rey justo al condenar severamente al rico sin corazón, antes que acabar de pronunciar su propia sentencia. Así, Nathan apuesta sobre la alta idea que David se hace de su misión real para con- 
ducirle a reconocer cuan inicua puede ser en realidad una vez quitado el velo de las apariencias. La treta profética es tan eficaz como aquella de David contra Urías, pero esta vez, esta es positiva porque, lejos de eliminar un obstáculo, ella permite más bien que un hombre progrese hacia la lucidez y la justicia. Se percibe claramente el contraste con la treta perversa de David.

\subsection{Abram y el faraón (Génesis. 12, 10-20)}

No por que la treta de David sea la de un poderoso, es mala. En efecto, la Biblia puede del mismo modo calificar de negativa la treta de un débil. En el comienzo de la historia de Abraham -quien se llama todavía Abram-, el narrador hace énfasis sobre una aventura ocurrida en Egipto. Empujado por el hambre Abram deja el pueblo de Canaan que Dios le había prometido para refugiarse en Egipto. Al llegar allí, otro temor le acosa. La belleza de su mujer Sarai constituye, cree él, una amenaza para él mismo: $Y$ como se aproximaba a entrar en Egipto, este dice a Sarai, su mujer: "Te lo ruego yo sé que tú eres una mujer bella a los ojos. Si los egipcios te miran ellos dirán: "Es su mujer" y ellos me mataran pero a ti de dejaran vivir. Di, te lo ruego, que tú eres mi hermana a fin de que esto sea bueno para mí gracias a ti y que yo pueda seguir vivo" / Mi deseo por tu causa". Y cuando Abram entró en Egipto, los egipcios vieron a la mujer que era muy bella. Y los príncipes del faraón la vieron, y la albergaron cerca del faraón y la mujer fue retenida en la casa del faraón. Y Abram tuvo benevolencia gracias a ella, y tuvo grandes y pequeños rebaños y asnos y sirvientes y domésticos y burras y camellos. (Génesis 12, 11-16)

La trampa de Abram funciona de maravilla y permite que se realice su propio deseo exorcizando sus temores. Pero las cosas cambian porque Adonai interviene llenando de llagas al Faraón y a los suyos para hacerle comprender que algo no está bien en su casa. Habiendo descubierto el problema, El faraón despide a Abram por haberle hecho reproches claros y haberle dado su mujer. De este modo, aquel que Adonai acaba de elegir para llevar la vida "a todas las familias de la tierra $(12,3)$ "ha sembrado únicamente la muerte hasta ser alejado como si atrajera la mala suerte que no rinde a Faraón a pesar de las riquezas que le ha dado (12,17-20). Pero ¿cuál es la razón de este fiasco del Patriarca? El narrador no 
explica este punto, pero el contexto de la escena permite decir un poco más. A través de esta estratagema, Abram intenta deshacerse de lo que no es más que un fantasma, en realidad. En este relato él no conoce a los egipcios y por lo tanto, él les da a priori intenciones asesinas que ellos no las tienen, como nos lo muestra el fin de la historia. Pero no solo que él miente, sino que llega hasta a sacrificar a su propia mujer, esperando sacar un buen provecho de la situación. Todo esto, porque está seguro de tener razón, además no tiene el coraje de tomar riesgos y prefiere optar a primera vista por la seguridad. La trampa no trata de hacer evolucionar las cosas hacia más abundancia de vida o de humanidad para todos. Esta sirve solamente para protegerlo, pase lo que pase a los otros.

\section{Los buenos engaños}

\subsection{Tamar y Juda (Génesis, capítulo 38)}

Si el engaño se vuelve malo, como ocurrió con David y Abram, cuando este corresponde a la voluntad exclusiva de salvarse a sí mismo, inclusive en detrimento de los otros que se encuentran, en consecuencia, sumergidos en la mala suerte o la muerte, este será juzgado como positivo, si permite que la vida salga triunfante para un máximo de actores. Este es, ciertamente el caso de Tamar. Esta mujer estuvo casada en primeras nupcias con un hijo de Judá, Er, quién desapareció prematuramente. Según la costumbre, el hermano del muerto debe unirse con la viuda para darle un hijo que llevaría el nombre del difunto. Así que Juda pide a su segundo hijo, Onan de cumplir con ese deber. Onan tiene relaciones sexuales con su cuñada, pero practica el coito interruptus para no dar descendencia a su hermano mayor. Dios lo hace morir también. Ignorando todo, Juda piensa que es la mujer quien hace morir sus hombres. En lugar de entregar a Tamar a su tercer hijo Shéla, él la devuelve a su padre, pretextando que Shéla es aún demasiado joven. Al cabo de un tiempo, la mujer comprende que esta es una treta de Judá, y que nunca tuvo la intención de entregarle a Shéla. Pero ella está decidida a tener lo que considera un derecho, esto es, un hijo de su primer esposo. Sabiendo que la mujer de Judá había muerto y que el tiempo de duelo había terminado, esta se disfraza con el velo de una prostituta y va a esperar a Judá a un lugar por el que ella sabe que va a pasar, imaginando el 
deseo de este hombre que ella cree frustrado. De hecho, en cuanto Judá nota la presencia de la prostituta, este le pide estar con ella sin reconocerla gracias al velo que le oculta el rostro. Convienen en un precio: un cabrito. Mientras tanto la mujer pide una garantía: un sello, una insignia y un cetro -tres signos de identidad, de alguna forma. Después del acto ella desaparece en el paisaje y Judá busca en vano a la prostituta para darle el cabrito y recuperar la garantía. Tres meses más tarde, el embarazo comienza a ser evidente, y las gentes denuncian a Tamar frente a Judá quién según la regla, siempre tiene derecho sobre ella. Judá la condena entonces a ser quemada viva. Pero en el momento de ser conducida a la hoguera, Tamar envía a Judá su garantía, diciéndole que estas pertenecen al hombre de quién ella está embarazada. Entonces Judá reconoce su falta, e indulta a la mujer quien, seis meses más tarde, le da gemelos. Reconocemos la astucia de la historia con las características corrientes: el juego sobre el deseo del otro, la puesta en escena que modifica las apariencias, el riesgo calculado, así como la habilidad en el uso de la palabra. Pero esta astucia es objeto de una apreciación positiva de aquel que, en este caso, es la víctima, Judá. ¿Podemos notar lo que le vale este honor, sabiendo que la maniobra violó una ley importante, aquella del incesto? Lo que vuelve la treta positiva, creo yo, es que esta intenta hacer evolucionar positivamente una situación de inercia, de parálisis -aquella de la mujer enclaustrada en casa de su padre -y de muerte - aquella de Judá que por miedo de ver morir a Shéla, prefiere privar para siempre su descendencia. Es de este modo que la mujer juega sobre el deseo frustrado, desilusionado, de júbilo y de vida que su suegro no puede liberar que no sea con una prostituta, para impedir que este sentimiento se vuelva un obstáculo de por vida. Ella intenta de este modo inclinar la balanza a su favor, a su propio deseo, aunque así se arriesgara a morir. Pero al final, todos ganan: la mujer que procrea, los hijos que podrán nacer, y también Juda quien recibe de Tamar dos hijos en lugar de aquellos que murieron.

\subsection{Un Dios astucioso (Éxodo 14)}

No puedo terminar esta rápida panorámica de la astucia en el Antiguo Testamento sin evocar una astucia divina, astucia presentada positivamente por el narrador del libro del Éxodo, incluso si nos 
viéramos seriamente tentados a juzgar negativamente a semejante Dios. Una especie de conexión se establece entre Adonai y Faraón. Por diez veces, a través de Moisés, Dios ha invitado al Faraón a liberar a su pueblo. Este ha intentado convencerle enviándole las célebres plagas, y el Faraón ha estado, varias veces a punto de ceder. Pero ha preferido la testarudez, a riesgo de ver a su pueblo sufrir miles de muertes. Cuando él mismo es tocado al ver morir su primogénito, cede al fin y deja partir a los israelitas. Pero Adonai no se queda ahí, pues quiere liberar definitivamente a su pueblo de este tirano que lo había reducido a la esclavitud y que exterminaba a todos los niños varones desde la más tierna edad.

Y Adonai habla a Moisés: "Habla a los hijos de Israel, y que venga a acampar delante de Pi-Hahirôt entre Migdol y el mar, delante de Baal-Sefón; es al frente que ustedes acamparán, cerca del mar; entonces Faraón dirá de los hijos de Israel: "Ellos están aislados en el país, el desierto los rodea"; y yo endureceré el corazón del Faraón y él les perseguirá y, de tal modo, yo me glorificaré a expensas de Faraón y de toda su armada y Egipto conocerá que yo soy Adonai." Y así lo hicieron. Se anuncia al rey de Egipto que el pueblo había huido y el corazón de Faraón y de sus servidores fue cambiado en sus sentimientos hacia este pueblo y dijeron: "¿Qué hemos hecho dejando a Israel dejar nuestro servicio?" $Y$ él apertrechó sus carros y tomó su pueblo consigo, seis cientos carros de élite, todos los carros de Egipto y un tercio de hombres en cada uno de ellos. Así Adonai endureció el corazón de Faraón, rey de Egipto, y se puso a perseguir a los hijos de Israel que estaban a punto de ser libres..." (Éxodo 14, 1-8). Conocemos la continuación: una vez que Faraón se reúne con los israelitas, Moisés abre el mar bajo la orden de Adonai, el pueblo entra y los egipcios entran juntos en su persecución. Entonces Adonai hace que se vuelva a cerrar el mar sobre Faraón y los suyos haciendo que las aguas los traguen.

Tenemos aquí el despliegue de una astucia estratégica: Adonai atrae a Faraón a una ratonera haciéndole creer que va ha recuperar sus esclavos en fuga, y contando con sus ansias de vencer y su aplomo incomparable, para sorprenderlo y deshacerse de él lo hace presa de su propio egoísmo. De este modo para que triunfe su deseo de liberar este pueblo que clama hacia él desde el fondo 
de su desesperación, Adonai utiliza el deseo de Faraón. Más exactamente, su maniobra juega sobre la palanca que constituye la psicología propia de un dictador tal como Faraón. Un tirano que no tolera ver que alguien lo resista. Toda resistencia, real o no, refuerza su determinación y le conduce a endurecer su posición. La voluntad liberadora de Dios, contrastando la voluntad esclavista del Faraón, lo endurece de golpe en su obstinación -lo que el narrador sintetiza al decir que Adonai endurece el corazón de Faraón. Pero lo que hay que tomar en cuenta, es la estratagema de Dios que hace caer al Faraón en su propia trampa de orgullo. En el contexto de la primera parte del libro del Éxodo, esta astucia viene a consagrar la victoria de aquel que quiere la libertad y la vida sobre aquel que esclaviza y que siembra la muerte. Este termina por cosechar muerte y su poder de muerte perpetua puesta fuera de combate, mientras que sus víctimas recuperan su libertad y su dignidad. Es bajo este lente, que la referida treta se ve positivamente, a los ojos del narrador del Éxodo.

\section{Conclusión}

A modo de conclusión, yo quisiera reunir rápidamente los principales resultados de esta panorámica. En las narraciones bíblicas que yo he abordado, el engaño o la astucia, es siempre el acto de alguien que quiere salir de un mal paso sea este real o imaginado o que quiere ayudar a un aliado. El problema es a veces anodino, como es el caso de Laban, pero en la mayoría de las veces es grave, y compromete incluso peligro de muerte (Abram, los gabonitas, Adonai e Israel). En general, el engaño se presenta como una alternativa o un recurso extremo, cuando esto es imposible (los gabonitas, Abram, Tamar) o tiene el riesgo de volverse contraproducente (Laban, David). Pero a veces, la astucia es aliada de la fuerza, sea para disfrazarla (David y Urías) o para secundarla (Dios y Faraón).

De todos modos el engaño aparece como una fuerza. No solo esta puede ser la de los débiles, sino que puede igualmente reemplazar o sostener la fuerza de los poderosos. Esta fuerza obtiene su eficacia de su capacidad de utilizar el deseo del otro, su narcisismo, su sentimiento de confianza, de seguridad o de poder, de 
sus características psicológicas, para desviar en su provecho, contra aquel que se deja engañar. Pero muchas de las veces es un juego riesgoso que supone a la vez audacia y cálculo, sutileza y sentido de adaptación. Ello implica siempre, que se juega sobre las apariencias para inducir al error del otro, de ahí la necesidad de la puesta en escena o la teatralización, o la simulación, con un uso más o menos equívoco del lenguaje: halagos, recurso a la ficción, a las insinuaciones, a la mentira -y aquí, todo lo que sirve a "hacer creer" que es bueno.

En fin, para lo que es la apreciación ética del engaño, las narraciones no enuncian jamás las razones precisas que vuelven este 0 aquel engaño como bueno o malo. De este modo, el narrador, hace un llamado a la sagacidad del lector. A mi juicio un engaño es malo cuando lo que busca es solamente su bienestar personal, preservar las apariencias de modo que el único beneficiario sea uno mismo, en detrimento de los otros que son para él, simples juguetes de su deseo. Al contrario cuando el engaño, permite dar a un máximo de individuos involucrados, un mejoramiento de vida, cuando tiende a la humanización, a dar lucidez, justicia, ella se beneficia de un juzgamiento positivo. Es que, en este caso, ella no juega con la confianza del otro para abusar, sino como en el la trampa de Tamar o de Nathan, para conducirle a un bien que él no percibe, encerrado como está en su lógica mortífera. Solo el Dios del paso del mar se escapa en parte de este modelo. ¿Será que el tirano a quien Él se opone es irrecuperable, o que Dios no es del todo moral? 